\title{
Making Conditional Cash Transfer Programs More Efficient: Designing for Maximum Effect of the Conditionality
}

\author{
Alain de Janvry and Elisabeth Sadoulet
}

\begin{abstract}
Conditional cash transfer programs are now used extensively to encourage poor parents to increase investments in their children's human capital. These programs can be large and expensive, motivating a quest for greater efficiency through increased impact of the programs' imposed conditions on human capital formation. This requires designing the programs' targeting and calibration rules specifically to achieve this result. Using data from the Progresa randomized experiment in Mexico, this article shows that large efficiency gains can be achieved by taking into account how much the probability of a child's enrollment is affected by a conditional transfer. Rules for targeting and calibration can be made easy to implement by selecting indicators that are simple, observable, and verifiable and that cannot be manipulated by beneficiaries. The Mexico case shows that these efficiency gains can be achieved without increasing inequality among poor households.
\end{abstract}

Conditional cash transfer programs targeted to poor households have become widely used, in particular to induce beneficiary households to invest in their children's human capital. The approach presumes that the supply side of social services for education and health is in place and that stimulating demand through income effects is insufficient to induce major changes in human capital investment (Bourguignon, Ferreira, and Leite 2002). Instead, a condition that transforms the income effect into a price effect needs to be attached to the cash transfer. In this case, receiving the transfer requires meeting school attendance and health practice requirements.

This approach has been hailed as a major innovation in organizing povertyreduction programs. Well-known programs that follow this approach include Progresa (now called Oportunidades) in Mexico, Bolsa Escola and Bolsa Familia in Brazil, Red de Protección Social in Nicaragua, Programa de Asistencia

Alain de Janvry and Elisabeth Sadoulet are professors in the Department of Agricultural and Resource Economics at the University of California at Berkeley. Their e-mail addresses are alain@are.berkeley.edu and sadoulet@are.berkeley.edu. They are grateful to Harold Alderman, Jean-Louis Arcand, Gabriel Demombynes, Frederico Finan, Patrick Guillaumont, Sylviane Jeanneney-Guillaumont, John Maluccio, Martin Ravallion, Kalanidhi Subbarao, and Miguel Szekely for their helpful comments.

THE WORLD BANK ECONOMIC REVIEW, VOL. 20, NO. 1, pp. 1-29

doi:10.1093/wber/lhj002

Advance Access publication February 1, 2006

(C) The Author 2006. Published by Oxford University Press on behalf of the International

Bank for Reconstruction and Development / THE WORLD BANK. All rights reserved. For permissions, please e-mail: journals.permissions@oxfordjournals.org. 
Familiar in Honduras, the Program of Advancement through Health and Education in Jamaica, Food-for-Education in Bangladesh, and Subsidio Unico Familiar in Chile (Ravallion and Wodon 2000; Skoufias 2000; Morley and Coady 2003; Rawlings and Rubio 2005). Some of these programs have become very large and expensive. In 2004 Oportunidades served 4 million families at a cost of \$2.2 billion. In 2001 Bolsa Escola covered 4.8 million families at a cost of $\$ 700$ million. While few programs have been rigorously evaluated, Progresa was found to have a positive impact on education (Schultz 2004) and health (Gertler 2004). However, almost no analysis has been conducted on the effectiveness of alternative program designs in achieving these results, despite the large sums spent to obtain them. This issue is addressed here by analyzing whether better targeting of qualifying poor households and better calibration of the levels of cash transfers could help raise program efficiency.

Conditional cash transfer programs have a dual objective: immediate poverty reduction through transfers and long-term poverty reduction through investment in human capital. Efficiently meeting the first objective requires the transfers to be accurately targeted to poor households-a difficult task not addressed here (van de Walle 1998; Alderman 2001, 2002; Ravallion 2003). Meeting the second objective requires accurately selecting among poor households to minimize the efficiency leakages from payments to children already highly likely to attend school without a transfer (as opposed to children who will attend school only because of the transfer) and offering a level of transfer that is sufficient to meet the opportunity cost of the change in behavior, thus securing a high uptake while minimizing project costs. The specific concerns addressed here are the definition of targeting and calibration rules that can be easily implemented and that are cost-effective and transparent, and the potential tradeoffs between efficiency gains through implementation of these rules and higher inequality in transfers among poor households.

Progresa is used to explore these alternative program designs. Efficiency gains of 29-44 percent over the current program are found to be possible without increasing inequality among poor households.

\section{The Efficiency Issue in Progresa}

Progresa is a conditional cash transfer program for human capital formation targeted to poor rural children. It consists of three closely related components to address education, health, and nutrition issues: (a) a monetary transfer to each child under age 18 who regularly attends school between the third year of primary school and the third year of secondary school and who regularly visits a health center, (b) basic healthcare for all family members, and (c) nutritional supplements for children and women in need.

Progresa was introduced in 1997 and by 2000 fully covered marginal rural municipalities, reaching 2.6 million families. The budget for 2000 was $\$ 950$ million-44 percent of it for education transfers, which benefited approximately 
1.6 million children in primary school and 800,000 in secondary school (Coady 2000).

The transfers that Progresa families receive significantly increase their income-by an average of 22 percent. Progresa has explicitly targeted poor households in marginal rural areas of Mexico. The purpose here is not to question this targeting, which corresponds to Progresa's objective of transferring resources to poor families. The purpose is to explore whether, for a given budget constraint, targeting and calibrating transfers to poor households can more efficiently increase school participation. Consequently, Progresa's education component is used as a laboratory to explore alternative targeting and calibration rules. The idea is to derive lessons from this richly informed experiment that can be applied to Progresa and to other conditional cash transfer programs where severely limited budgets make targeting critical.

To measure its impact, Progresa selected a sample of 506 marginal communities containing 24,000 households and 17,000 children eligible for transfers and surveyed them a year before the program started and, subsequently, every six months over three years. Information was collected on individual, household, and community characteristics. The sample design consists of the random selection of 320 treatment communities and 186 control communities. The analysis is restricted to children in school in October 1997. Twelve percent of eligible children had dropped out of school by that time, some several years earlier, and while the program helped bring some of them back to school, this one-time effect at the onset of the program is not the focus of the analysis. The sample was further restricted to the 2,242 poor children who graduated from primary school in the summer of 1998 and faced the decision of whether to continue to secondary school. These data are used to estimate a model of the school enrollment decision that captures, in particular, the impact of Progresa transfers, paying particular attention to heterogeneity of conditions among children. Alternative targeting and transfer programs are then simulated and their efficiency is compared.

\section{Focusing on Entry into Secondary School}

A simple analysis of the overall Progresa budget suggests that an efficient program for school enrollment should focus strictly on the transition from primary school to secondary school, a point already suggested in the International Food Policy Research Institute evaluations (Skoufias 2000; Coady 2000; Schultz 2004).

The conditional transfer offered to each child is calculated according to the program's rules. ${ }^{1}$ The program has a schedule of education transfers that increase as children progress to higher grades and that are higher for girls than for boys in secondary school (table 1). There is, however, a maximum total

1. The 'conditional transfer' is the exogenous amount that a child would receive from Progresa if he or she was in a treatment community and attended school. It depends on the gender and grade of the child and the household's demographics. At the household level the conditional transfer is the total amount that the household would receive if it was in a program community and complied with all Progresa rules. 


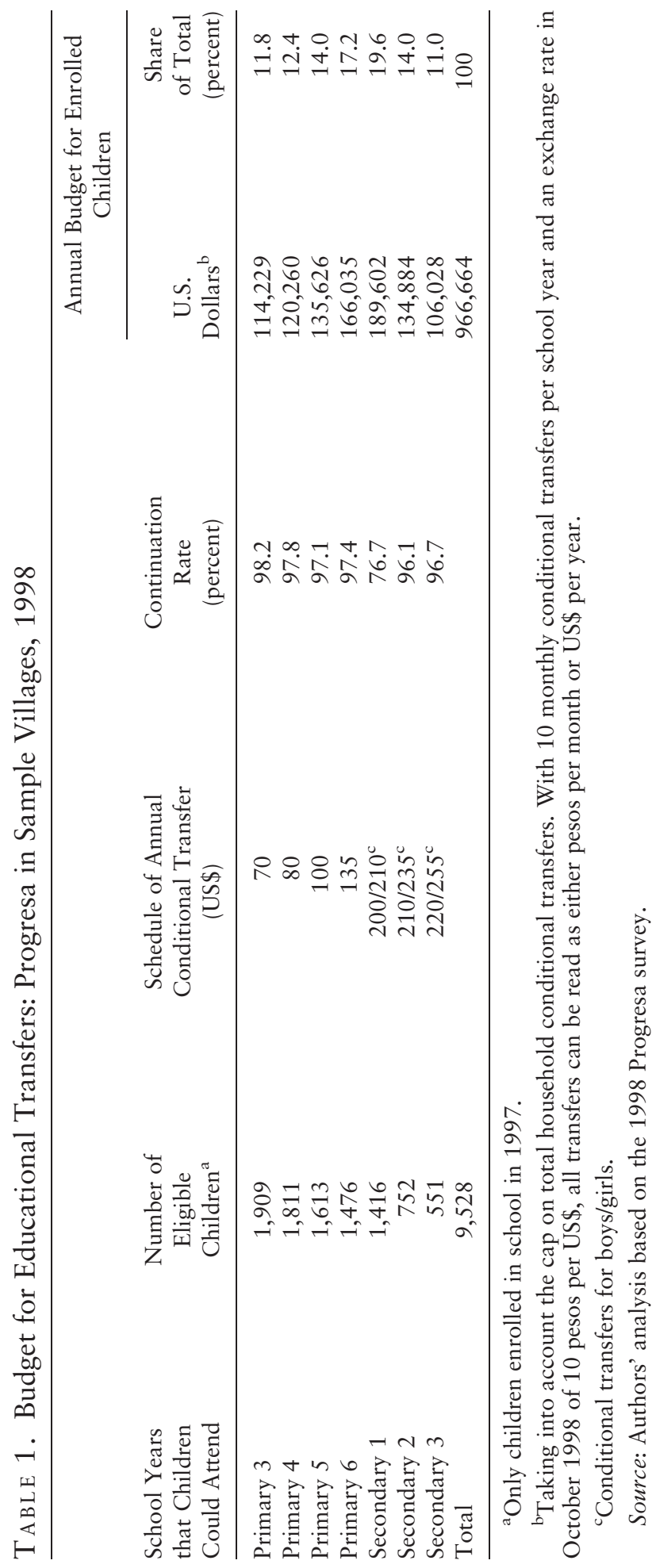


conditional transfer that each household can receive, set at $\$ 625$ a year in 1998 (including \$100 for nutrition). ${ }^{2}$ In the sample, 13.4 percent of eligible children are subject to the household transfer cap. Using the proportionality rule that Progresa applies, the conditional transfer corresponding to each child is calculated by scaling down all the education transfers in a household subject to the cap by the same factor. ${ }^{3}$ Among the children graduating from primary school, 28 percent are subject to the cap, and the conditional transfers vary from $\$ 100$ to the full $\$ 200 / \$ 210$, with an average of $\$ 169$. The budget for education transfers in the sample treatment communities is calculated using these conditional transfers and the enrollment status of each child (table 1). The budget would be 17 percent higher, with no cap on total household conditional transfer. Taking into account these caps, transfers to primary school children account for 55.4 percent of the total budget for education transfers and the first year of secondary school for almost 20 percent.

Other studies show that Progresa's conditional transfers increase continuation rates at all grades (Behrman, Sengupta, and Todd 2001; de Janvry, Finan, and Sadoulet 2001; Schultz 2004). However, school continuation rates were already very high in both primary and secondary school before the Progresa intervention (figure 1). The increase in continuation rates that result from the conditional transfers is only around 1 percentage point in primary school and half a percentage point in the second and third years of secondary school. This suggests that, from an efficiency standpoint, Progresa is unnecessarily expensive for primary school, with 96 school-attending children paid for each child that is retained in school by the conditional transfer incentive, for an implied effective cost per additional child attending primary school of $\$ 9,600$. Assisting the 3-4 percent of children who drop out of school at each grade level would require a very different program. Eliminating all transfers to primary school students would have saved 55.4 percent of the education transfer budget, or more than $\$ 230$ million of the $\$ 950$ million budget in 2000 .

The critical problem in terms of education achievement occurs at entry into lower secondary school. Thus the analysis here continues only for secondary school.

\section{The Efficiency of Progresa's Education Transfers}

There are two sources of inefficiency in a conditional cash transfer program that need to be optimally reduced. The first is paying people for what they were already going to do. With Progresa, this is obvious in primary school. But the problem also arises in secondary school: 64 percent of the poor children who graduate from primary school would enter secondary school without a transfer. Reducing this efficiency leakage requires being able to predict who will not

2. This cap was introduced so that the program does not induce a fertility response.

3. For households subject to the cap all conditional transfers are scaled down by a common factor so that they add up to the cap. This prevents the households from keeping a child out of school without penalty. 
FIgURE 1. School Continuation Rates of Poor Children in Sample Communities

Continuation rate $(\%)$

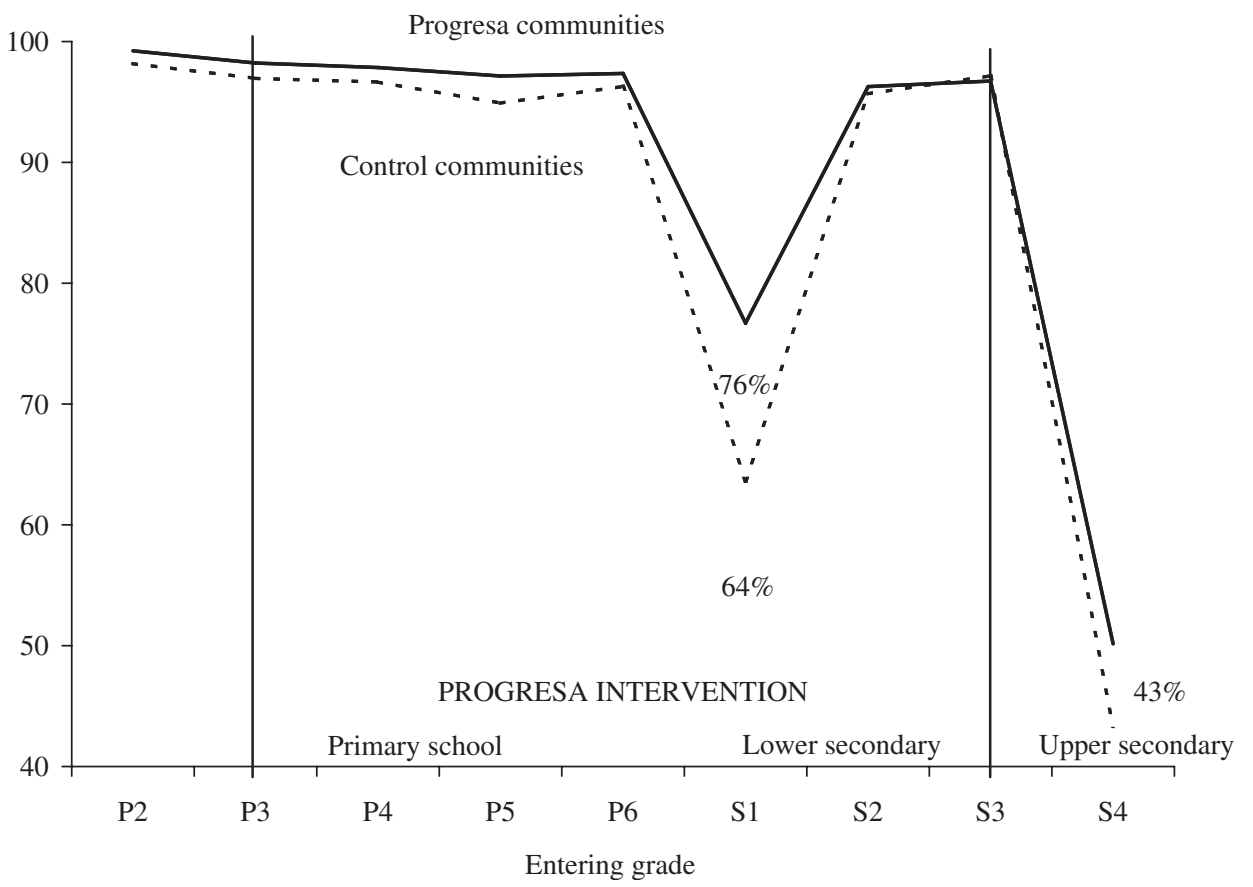

Source: Authors' analysis based on the 1998 Progresa survey.

continue in school, using a model for the probability that a given type of child will enroll in school. Because such predictions are inevitably noisy, there is no way to completely avoid this inefficiency. ${ }^{4}$ The challenge, however, is to reduce it by not targeting children most likely to attend school anyway.

The second source of inefficiency comes from offering transfers that are either too high or too low relative to the minimum amount needed to induce the conditional action. As shown later, the simple difference estimation of the impact of Progresa indicates that the program raised the enrollment rate from 63.6 to 76.6 percent. The conditional transfers offered were thus sufficient for the 13 percent of children in the sample who were attracted to enroll in secondary school and would not have done so otherwise. Could a smaller conditional transfer have had the same effect? For the 23.4 percent that did not take the conditional transfer, would a higher transfer have induced them to accept the offer? If so and if these children can be identified, should the conditional transfer offered to them be increased?

4. This inefficiency concept is analogous to the issue of fungibility with inframarginal transfers, whereby beneficiaries substitute other commodities for those subsidized by the program, meaning that the program has no real effect on total consumption of the targeted commodity. 
If there were a clear opportunity cost to children's time in school, the subsidy could be calibrated to match it. For Progresa the transfer is 40 percent of what children of the same age earn when they work. But the opportunity cost of children's time at school is not easy to calculate. Less than 30 percent of the children who drop out at the end of primary school work during the subsequent 18 months (45 percent of boys and 10 percent of girls), increasing to 35 percent (55 percent of boys and 12 percent of girls) the following year. Lack of money or need to work is the most common reason given for not continuing school (57 percent), but other important reasons are that the child does not like school or does not learn (23 percent) and that the school is too far away (13 percent).

The Progresa randomized experiment allows the estimation of the children's response function, which is necessary to design the transfer schedule that maximizes return to the program. Since no experiments were conducted to observe the response to different levels of conditional transfers, the cap on total conditional transfers to a household is used to infer the marginal response to varying conditional transfer amounts.

Dealing with these two sources of inefficiency requires an accurate predictive model of the probability of attending school as a function of the characteristics of the child, the household, and the community and of the amount of the conditional transfer offered. The analysis here concentrates on entry into secondary school since that is where the conditional transfer can induce an important behavior change that results in efficiency gains.

The conditional transfers offered to children in second and third years of secondary school are not questioned for two reasons. First, these conditional transfers are part of the expected benefits of entering secondary school, and the measured impact of Progresa thus includes their effect. Second, while very high continuation rates are observed in secondary school, they are for a selected group of children who voluntarily entered secondary school without any subsidy in 1998, before the program was in place. Other children who are induced to enter secondary school with a conditional transfer are very unlikely to continue at the same rate if the subsidies were discontinued. No experimental design allows this particular continuation rate to be studied here because Progresa always supported the first three years of secondary school. The safe bet is that whatever transfer is provided in the first year needs to be provided in all three years of secondary school (as is currently the case), and while in 1998 many fewer Progresa children were in the second and third years of secondary school than in the first year (because it was the first year of the program), these numbers should even out three years after program implementation. Thus the results of the analysis of the first year are applied to all three years of secondary school.

\section{A Model of Optimal Cash Transfer}

Let $P(X, Y)$ denote the probability that a child with characteristics $X$ and eligible for a conditional transfer $T$ will enroll in school. Eligibility is denoted 
by the index function $I \in[0,1]$. Children's characteristics are distributed according to the density function $f(X)$.

The allocation problem consists in choosing the eligibility status $I(X)$ and, if eligible, the conditional transfer $T(X)$ offered to a child with characteristics $X$, to maximize the gain in enrollment over the population:

$$
\max _{I(X), T(X)} \int[P(X, T)-P(X, 0)] I f(X) \mathrm{d} X
$$

subject to a budget constraint:

$$
\int P(X, T) T I f(X) \mathrm{d} X \leq B
$$

where $B$ is the budget available for the program. The first order condition for the optimal conditional transfer is that, for any eligible child $(I=1)$,

$$
P_{T}-\lambda\left(P_{T} T+P\right)=0
$$

where $P_{T}=\partial P / \partial T$ and $\lambda$ is the Lagrange multiplier associated with the budget constraint. This relationship states that the ratio of cost $\left(P_{T} T+P\right) \mathrm{d} T$ to enrollment benefit $\left(P_{T} \mathrm{~d} T\right)$ of a marginal increase in the conditional transfer $(\mathrm{d} T)$ is equal for all children. Hence, the cost of the marginal child brought to school is equal across children types $X$. Note that the cost has two terms. The first term, $P_{T} T \mathrm{~d} T$, is the transfer cost to the $P_{T} \mathrm{~d} T$ marginal children brought to school by the increase in conditional transfer. The second term, $P \mathrm{~d} T$, is the cost of giving the increase in transfer, $\mathrm{d} T$, to all $P$ children of the same type $X$, even though they enrolled in school with the initial transfer $T$. This is the marginal equivalent of the decomposition of the cost of transfers:

$$
P(X, T) T=[P(X, T)-P(X, 0)] T+P(X, 0) T
$$

where the first term is the cost of the transfers to the children brought to school by the conditional transfer and the second term the cost of transfers to the children with similar observable characteristics who would have gone to school anyway.

Given the optimal conditional transfer amount conditional on eligibility, the optimal eligibility rule is defined by:

$$
\begin{array}{cc}
I=1 & \text { if }[P(X, T)-P(X, 0)] T+\lambda P(X, T) T \geq 0 \\
I=0 & \text { otherwise. }
\end{array}
$$

The optimal allocation of a budget $B$ is thus the solution to the system of equations (2), (3), and (5).

In the particular case of a linear probability model, which is used in the empirical work here, the conditional expectation of the enrollment probability is: 


$$
E P(X, T)=X \beta+\delta_{0} I+X \delta T
$$

where $\delta_{0} I+X \beta T$ is the total impact of $T$ and $X \delta$, which includes a constant term, is the marginal impact of $T$. The presence of an intercept $\delta_{0} I$ is due to the fact that only conditional transfers of $\$ 100-\$ 210$ are observed, meaning that the linearity of the conditional transfer effect cannot be extended below that range to a 0 conditional transfer.

The optimal conditional transfer and eligibility criteria defined in equations (3) and (5) are:

$$
T=\max \left[\frac{1}{2 \lambda}-\frac{1}{2} \frac{X \beta+\delta_{0}}{X \delta}, 0\right]
$$

where $\lambda$ is the solution to the budget constraint in equation (2). The expression shows that both eligibility and the optimal conditional transfer for any given child are a function of the ratio

$$
\frac{X \beta+\delta_{0}}{X \delta}=\frac{E P(X, 0)+\delta_{0}}{E P_{T}} .
$$

The first term in the numerator is the expected probability that children with characteristics $X$ would attend school even without a conditional transfer, and the denominator is the marginal effect of the conditional transfer on the expected enrollment probability. Children will thus be eligible for and be offered high conditional transfers when they have a low initial probability of enrollment or a high enrollment response to a conditional transfer. This optimal conditional transfer is a function of all the characteristics $X$ that predict enrollment, albeit in a very nonlinear form.

Whether any program could use such a complex formula to compute conditional transfers is questionable. But it is a useful benchmark because it gives the maximum efficiency that could be reached with the observables $X$, and it will thus be computed in the empirical analysis that follows. Next, however, the optimal program is constrained to be linear and to use a small number of observable characteristics.

\section{An Implementable Conditional Cash Transfer Program}

To be useful for program implementation, eligibility rules need to be simple and transparent. Indicators used to determine eligibility, and the level of conditional transfers must be few, easily observable and verifiable, and nonmanipulatable by households. Simplicity and transparency are also important to ensure the political acceptability of a subsidy program (Schady 2002). Progresa uses grade and gender to set the schedule of conditional transfers (table 1). The objective is thus to simplify the formula in equation (7) established for the optimal conditional cash transfer program to a linear index on the basis of a few characteristics $Z$ of the children. 
The allocation problem lies in choosing the eligibility status and, if eligible, the conditional transfer to offer to each child to maximize the gain in enrollment over the population [equation (1)], subject to the budget constraint [equation (2)], and using simple linear formulas for eligibility and conditional transfer:

$$
T=Z \alpha \text { and } I=I\left[Z \gamma \geq \gamma_{\min }\right]
$$

where $Z$ is a subset of characteristics of the children and $\alpha, \gamma$, and $\gamma_{\text {min }}$ are parameters to be determined. As in the model above, optimal eligibility is defined by the sign of the optimal conditional transfer value:

$$
I=1 \Leftrightarrow T=\max (Z \alpha, 0)>0 .
$$

The parameters $\alpha$ are a solution to the maximization of a quadratic function:

$$
\max _{\alpha} \sum_{i \in E} m_{i} Z_{i} \alpha-\lambda\left[B-\sum_{i \in E}\left(P_{0 i}+\delta_{0}+m_{i} Z_{i} \alpha\right) Z_{i} \alpha\right]
$$

where $E$ is the set of eligible children, $m_{i}=X_{i} \delta$ is the marginal effect of the conditional transfer on child $i$ 's school enrollment, $P_{0 i}=X_{i} \beta$ is child $i$ 's enrollment probability without the transfer, and $\lambda$ is the Lagrange multiplier on the budget constraint. The conditional transfer formula in equation (9) is thus a simple linear combination of a few observed characteristics $Z$. It is similar to the scoring system used in many welfare programs, whereby characteristics $Z$ command scores $\alpha$ that add up to an aggregate score $Z \alpha$. In this case $Z \alpha$ determines not only eligibility but also the conditional transfer amount.

Important empirical questions are whether the use of this simple scoring schedule is close enough to the optimal conditional cash transfer schedule and what type I (exclusion) and type II (inclusion) errors are made in this implementation. These questions are addressed after the schedules are established.

\section{Predicting Enrollment}

In this section a predictive model of entry into secondary school is built. Although a probit and a logit perform better at high and low probabilities, a linear model is used here to avoid imposing heterogeneity on the impact of the conditional transfer through the functional form, since this will be an important determinant of the targeting rule. ${ }^{5}$ The sample of children finishing primary school and eligible for a Progresa transfer (defined as poor according to

5. In the simulation exercises that follow, the problem of predicted negative probability is never encountered (the majority of children have predicted probabilities above 0.4 ), but some predictions are above 1 , even without conditional transfer and more when applying conditional transfers. For simulation purposes these will be set equal to 1 . 
the Progresa welfare index) in both the control and treatment communities is used, and randomization in the selection of communities ensures that being in a treated community is orthogonal to the children's characteristics. ${ }^{6}$ The average treatment effect can thus be obtained simply by comparing the average enrollment rates of children in the two types of communities. However, the actual amount of conditional transfer offered to a child is not orthogonal to its characteristics because being subject to the cap rule and the corresponding household scaling factor are both a function of the children's age structure, which is likely correlated with household preferences that influence schooling decisions. The impact of the continuous treatment effect is thus estimated, controlling for the conditional transfer level.

The empirical equivalent to equation (6) is written as:

$$
S_{i}=\delta_{0} I_{v}+\delta I_{v} T_{i}+\beta_{0} T_{i}+u_{i}
$$

or

$$
S_{i}=\delta_{0} I_{v}+\delta I_{v} T_{i}+\beta_{0} T_{i}+X_{i} \beta+u_{i} \text {, with control variables } X_{i}
$$

where $S_{i}$ is a binary variable indicating the enrollment status of child $i, I_{v}$ is a dummy variable that indicates whether child $i$ lives in a treatment community, $T_{i}$ is the conditional transfer that child $i$ is eligible for under the program, and the control variables $X_{i}$ are child, household, and community characteristics.

The program increases the probability that qualifying poor children will continue to secondary school by 13 percentage points [table 2, column (1)]. As expected this is slightly higher than the estimated 8-9 percentage point increase in enrollment probability conditional on completed primary school (i.e., including children who had dropped out of school before the program started) obtained in other studies (e.g., Schultz 2004).

The value of the conditional transfer (variable $I_{\nu} \mathrm{T}_{i}$ ), which varies across children because of the cap on household transfer that affects 26 percent of the qualifying children, is used in column (2). Results show that the marginal effect of the conditional transfer is high (1.42 percentage points per \$10). Note that the imposed linear form gives a meaningful positive effect only for conditional transfers above $\$ 100$, which is not really restrictive because current conditional transfers are much higher. Adding a large number of child, household, and community controls in column (3) indicates that the main correlates of a child's secondary school enrollment are age of the child (negative), mother's literacy and the household's maximum education level (positive), the number of agricultural workers and self-employed workers in the household (negative), total expenditure (positive), and distance to school (negative). State effects are also important. Both models predict that the current $\$ 200$ conditional transfer increases the probability of enrollment by

6. The quality of the randomization is verified and documented in Behrman and Todd (1999). 


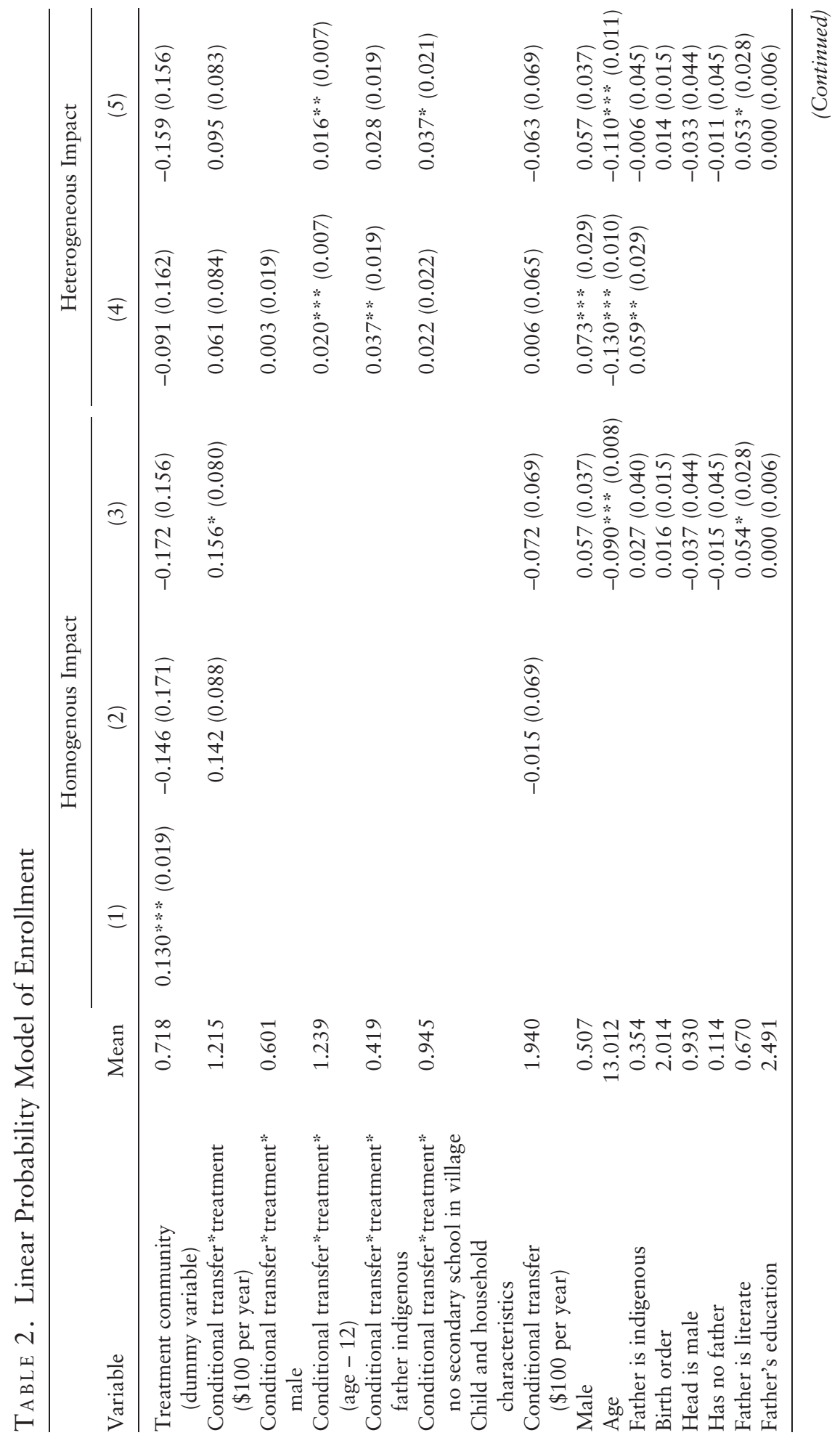




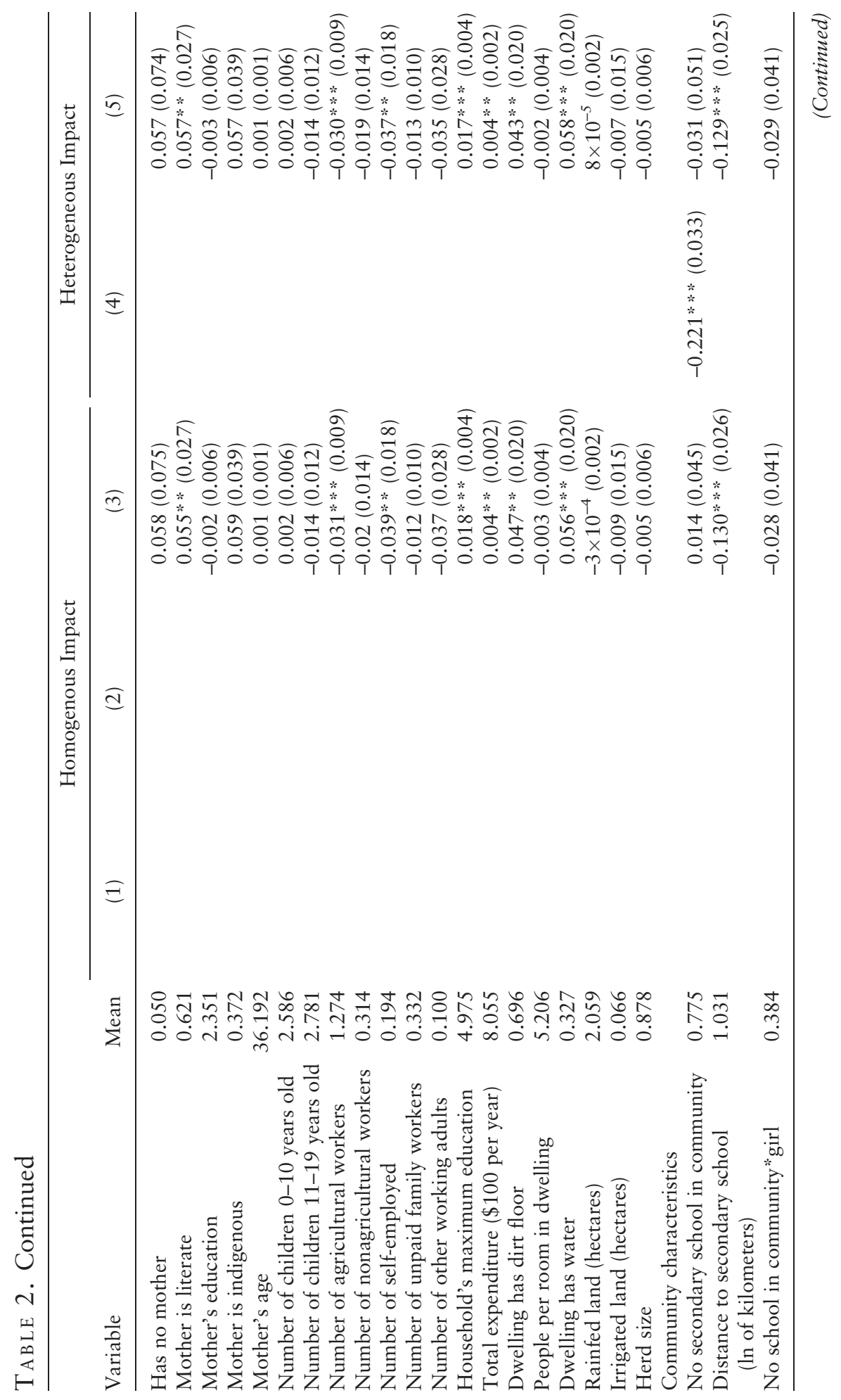




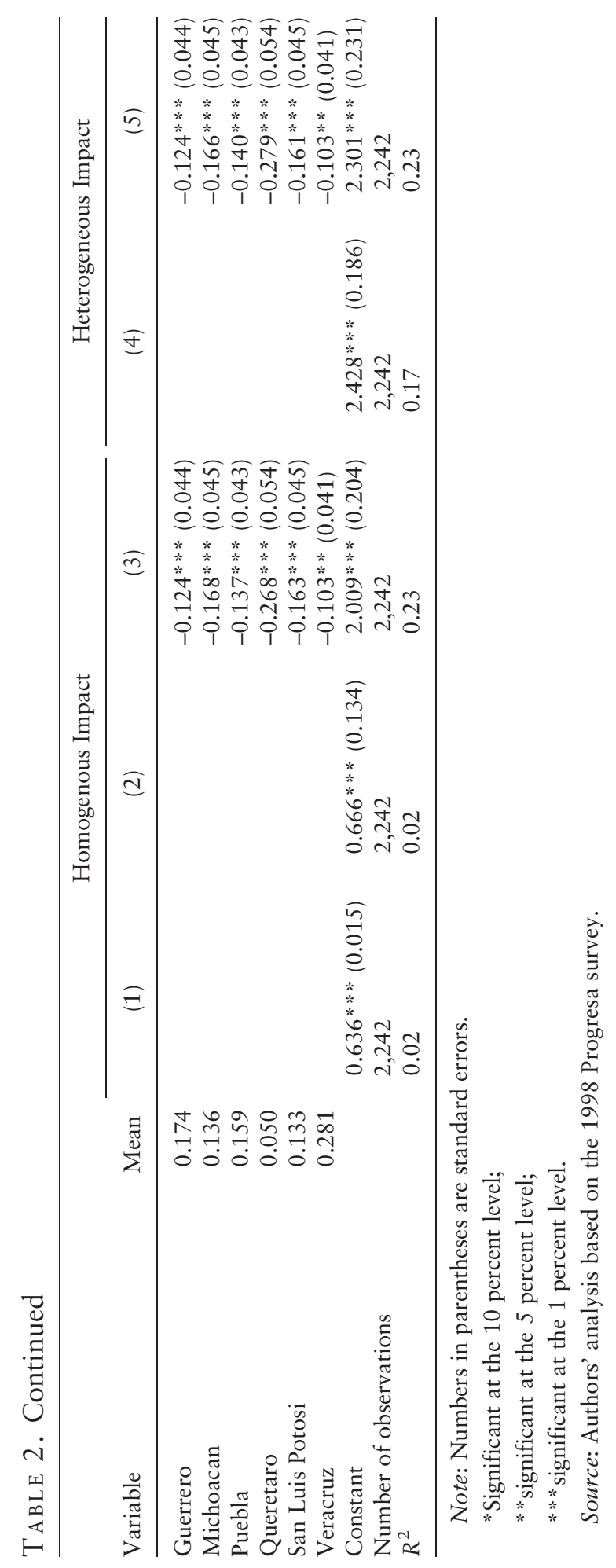


the same 14 percentage points (table 3), which confirms that the controls are orthogonal to the treatment. ${ }^{7}$

Columns (4) and (5) explore heterogeneity of impact across categories of children, with and without controls, focusing on the aspects of heterogeneity that may be usable for targeting purposes. They are the child's age, ${ }^{8}$ father's ethnicity, and whether there is a secondary school in the community. Progresa recognizes gender differences, which are not found to be important in explaining differential impacts of transfers on the decision to continue into secondary school. ${ }^{9}$ The results show that age, ethnicity, and presence of a school in the community all have large impacts on enrollment, both directly as controls and in affecting the impact of the conditional transfer. The results in column (5) are used as the predictive model to evaluate the impact of targeting on enrollment.

Heterogeneity implies large differences in the impact of a conditional transfer on enrollment across categories of children (table 3). For a 12-year-old boy with a nonindigenous father and a school in the community, the $\$ 200$ conditional transfer increases the probability of enrollment by only 3-4 percentage points. If he is two years behind normal progress, the conditional transfer increases the probability of enrollment by 10-12 percentage points. For a 12-year-old boy with an indigenous father or no secondary school in the community, the conditional transfer increases the probability of enrollment by 9-11 percentage points. Combining the features of being a boy, 14-years-old, with an indigenous father, and in a community with no secondary school means that a $\$ 200$ conditional transfer raises the probability of school enrollment by 23-24 percentage points. These large differences suggest that there can be efficiency gains by using some of these dimensions of heterogeneity to target conditional transfers-in the same way that Progresa uses gender differences to set conditional transfer levels.

One concern is that identifying the impact of the size of a conditional transfer on enrollment derives from observing children who are offered less than the full transfer due to the cap on total household conditional transfers. These children are, by definition, from households with more eligible children. To verify that the enrollment model for these households does not differ significantly from the model for smaller households, the estimation was compared with a model

7. Another interesting result in column 3 is the relative magnitude of the impacts of a conditional transfer $\left(I_{\mathrm{v}}\right)$ compared with a nonconditional transfer (household total expenditure variable) on enrollment. While the result is only suggestive because total expenditure is endogenous, the $\$ 200$ conditional transfer is associated with an increase in the probability of enrollment 17 times higher than an equal nonconditional transfer.

8. The age is centered on 12 years old, the median age for entry into secondary school, so that the coefficient on the direct variable is the impact on a 12 -year-old.

9. The lack of significance and very low point estimate of the male*treatment interaction variable (0.003 with standard error 0.002) are robust to many specifications, including both fewer and more interaction terms and several control variables. The term is thus dropped from the estimation in column 5. The often reported difference between boys and girls comes from estimations of enrollment rather than continuation rates. Coady (2000) finds that most of that difference comes from Progresa's very strong impact on girls' re-entry into the school system during the program's first year. 


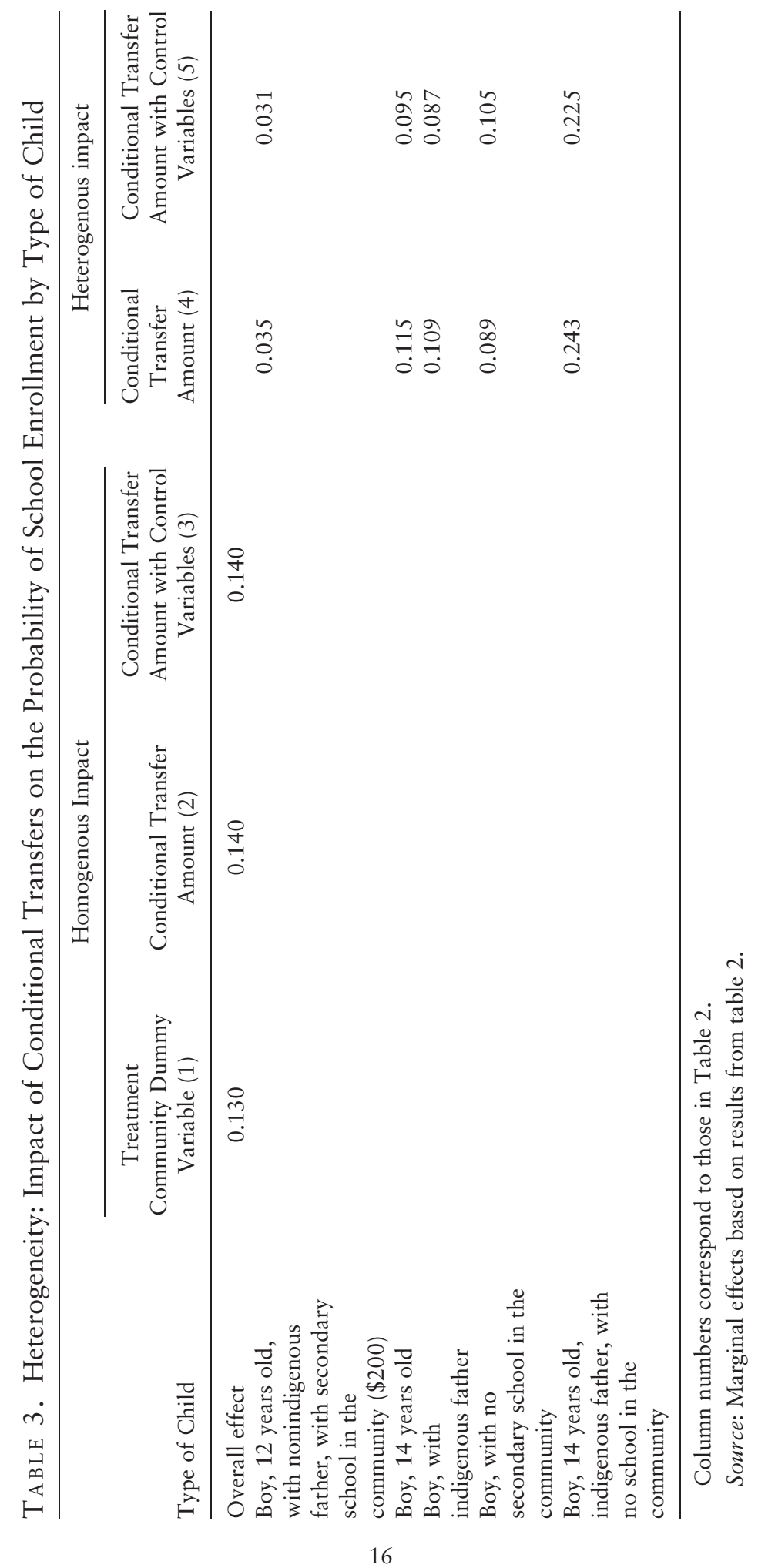


estimated for these children alone. The estimation is, as expected, more precise with the whole sample, but the parameters are neither individually nor globally significantly different between the two estimations (the p-values for the test of equality of the parameters on the conditional transfer variables are 0.49 without heterogeneity and 0.16 with heterogeneity), which confirms that the conditional transfer parameter was correctly identified. The orthogonality of the conditional transfer to all other variables was also verified by estimating different models for children in the treatment and control communities, and the parameters were checked to ensure that they are neither individually nor globally significantly different between the two estimations. Thus, the model can be used to predict behavior in the absence of a conditional cash transfer program.

\section{Comparing Conditional Cash Transfer Schedules}

Three targeting and calibration schedules are now analyzed to determine whether they can help raise the efficiency of conditional transfers in inducing school enrollment (table 4). Each program has the same total budget as the current Progresa program. This budget is calculated by predicting for each sample child the expected uptake (predicted probability) $\hat{E} P$ and summing the expected transfers $\hat{E} P . T$ to reach a total annual outlay of $\$ 322,000$ for the 2,242 sample children. ${ }^{10}$ The upper panel of table 4 reports the enrollment rates for all children and by category of children according to their 'risk level', that is, their predicted enrollment rates without any conditional transfer, or their eligibility status in the program. The lower panel reports some aggregate targeting and cost outcomes for the different schedules. These results are also represented in a graph of the enrollment probability of each program against the initial enrollment probability without a conditional transfer program (figure 2 ). The distance from the diagonal to each curve thus represents the gain in enrollment from the program with the corresponding schedule.

\section{Emulating Progresa: A Universal Uniform Conditional Cash Transfer Program}

The school enrollment rate without conditional transfer is 63.2 percent [table 4, column (1)]. Progresa's current universal conditional transfers with a cap and with differential values for boys and girls raise the probability of enrollment to 75.7 percent, a gain of 12.5 percentage points. The universal uniform conditional transfers program without a cap and without gender differences used as a benchmark for the subsequent simulations also raises the probability of enrollment to 75.7 percent [column (2)]. Under this program the conditional transfer

10. Another interesting exercise would be to define an efficient allocation of the total education budget of the current Progresa program. It would consist of reallocating the primary school budget to secondary school, thus doubling the budget for secondary school. A simulation of this budget reallocation shows that it would lead to almost universal secondary education with enrollment rates of 90.4-91.7 percent, depending on the rule used for transfer calibration. 


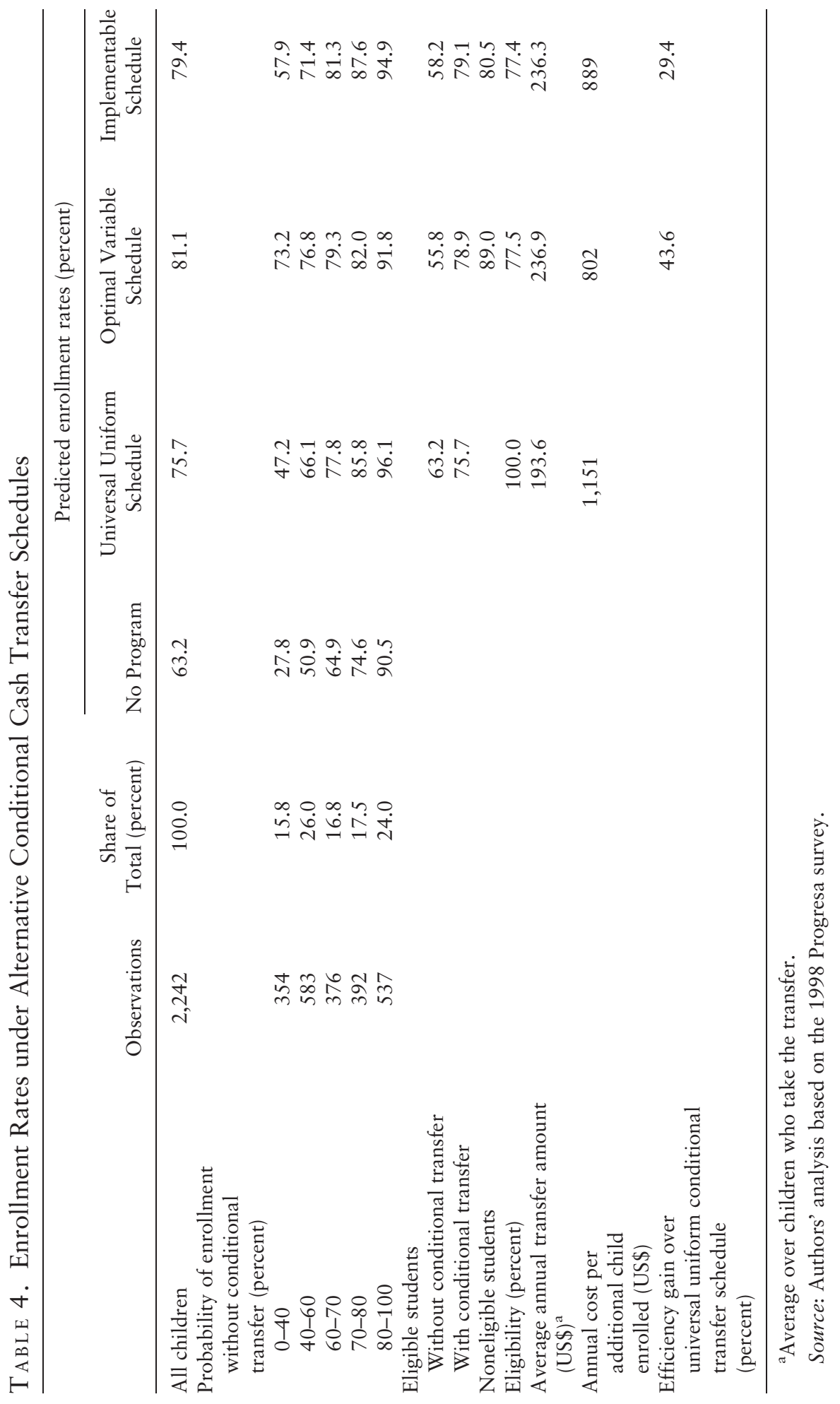


Figure 2. Impact of Alternative Conditional Cash Transfer Schedules on Enrollment Probabilities

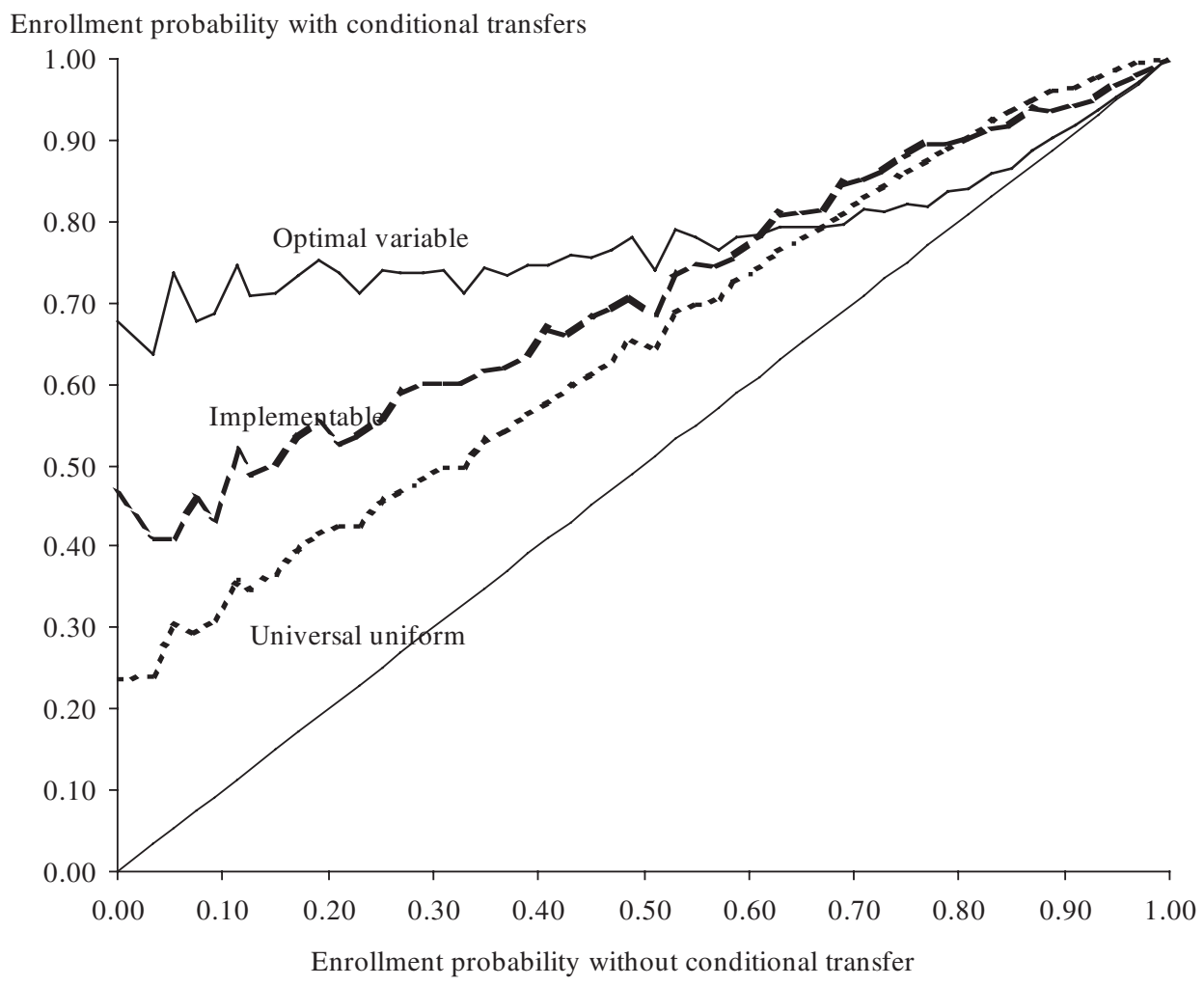

Source: Authors' calculations based on the 1998 Progresa survey.

per child is about $\$ 194$ a year. ${ }^{11}$ Because many children receive a transfer even though they would attend school without one, the cost per additional child enrolled is $\$ 1,151$ a year. Figure 2 shows that gains in enrollment due to the program are largest for children with a low probability of enrollment and decline as the enrollment probability rises.

Table 4 reports these gains, with enrollment probability rising from an average 27.8 to 47.2 percent, or 19.4 percentage points, for the children with probability of enrollment lower than 40 percent, while the gain is only 5.6 percentage points for those in the 80-100 percent category [columns (1) and (2)]. Gains are hence progressive in terms of the initial likelihood of going to school, even with a uniform conditional cash transfer program. This is the Progresa achievement that has been widely acclaimed in the literature. However, can better results be obtained by redefining the targeting and calibration of conditional transfers?

11. The level of the conditional transfer is determined by the Progresa budget, taking into account the uptake that it is predicted to induce. 


\section{An Optimal Variable Conditional Cash Transfer Program}

The second simulation implements the optimal variable conditional transfer program established in the model under the same budget constraint and taking into account heterogeneity in probability of enrollment and responses to transfers across children. Both eligibility and the optimal conditional transfer value are simultaneously determined. This is done by offering the conditional transfer defined in equation (7) to children of characteristics $X$. To compute the conditional transfer values, the estimated values for $\beta, \delta_{0}$, and $\delta$ in table 2 , column (5), are used, and the shadow value $\lambda$ of the budget constraint that balances the budget is found by tâtonnement. The resulting conditional transfers vary from $\$ 100$ to $\$ 350$, depending on the child's characteristics. Under this optimal variable program the conditional transfers to children with a low probability of attending school are increased, and children with high probabilities of attending school are targeted less because efficiency leakages are particularly high for them.

The best predictor model for enrollment [table 2, column (5)] is again used to predict enrollment for every child in the sample. Students eligible to receive a conditional transfer have an average predicted enrollment rate of 78.9 percent, compared with 55.8 percent, had they not been offered the conditional transfer. The noneligible students have an average predicted enrollment rate of 89 percent. Overall, the predicted school enrollment rate is now 81.1 percent, an efficiency gain of 43.6 percent over the universal uniform conditional transfer schedule. The optimal variable conditional transfer schedule almost equalizes the probability of enrollment among children with very different initial probabilities to values close to 70 percent (figure 2). The largest gains in probability of enrollment are thus captured by those with the lowest initial probabilities.

Figure 3 shows the distribution of children by initial enrollment probability without a conditional cash transfer program, superimposing the distribution of those that are eligible in the optimal schedule (shaded) and showing, by difference, the distribution of noneligible (unshaded). Under the optimal conditional transfer schedule eligibility is concentrated on children with low initial probabilities, while noneligible children all have initial probabilities above 70 percent. The optimal calibration of conditional transfers also favors those with low initial probabilities, trying to induce them to enroll in school with a higher conditional transfer. The conditional transfers decline as the probability of being enrolled in school without a transfer rises. There are, however, relatively few children with predicted low enrollment probability; most are in the 40-80 percent range.

Some 77.5 percent of children are eligible for a conditional transfer under the optimal variable schedule, with the average transfer about $\$ 237$, a 22 percent increase over the average transfer under the universal uniform schedule (table 4). The optimal schedule thus suggests raising the amount of the conditional transfer for children who are less likely to attend school while reducing it for children who are already likely to attend school without a conditional transfer. Since there are 
Figure 3. Eligibility with the Optimal Variable Conditional Transfer Schedule

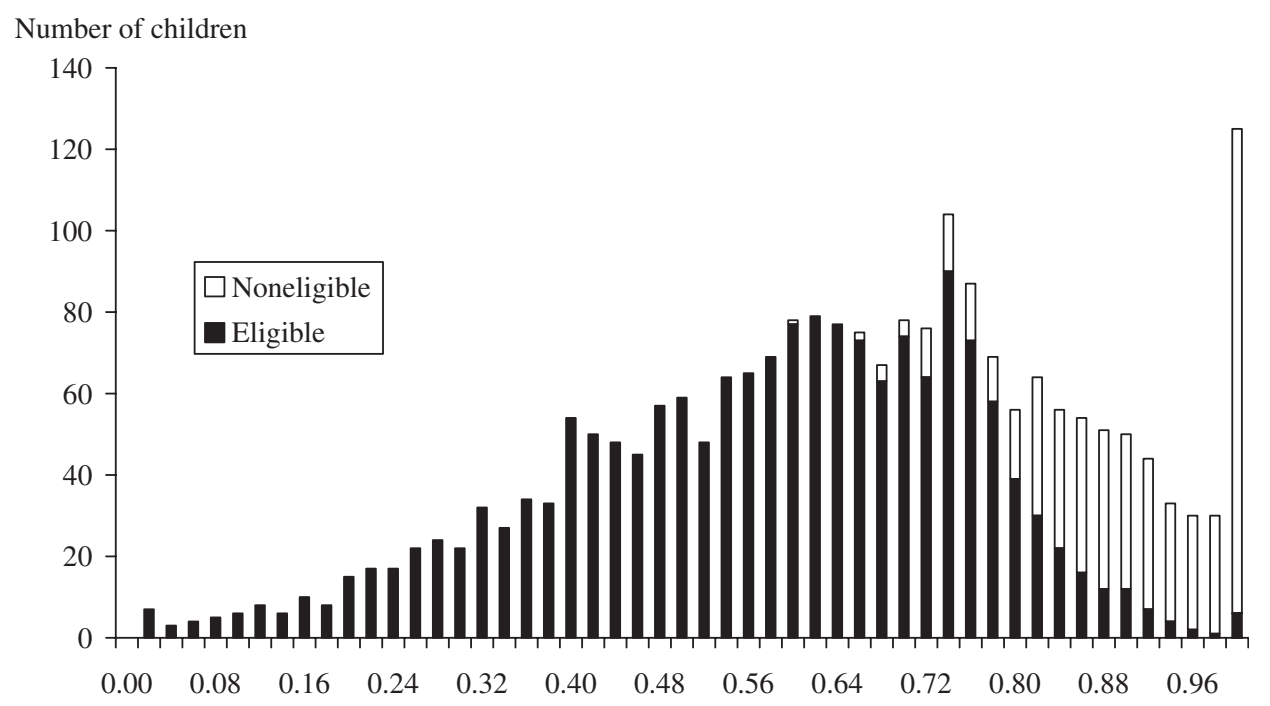

Enrollment probability without conditional transfer

Source: Authors' calculations based on the 1998 Progresa survey.

still efficiency leakages among eligible children, the cost per additional child enrolled is $\$ 802$, down from $\$ 1,151$ under the universal uniform conditional transfer schedule. Cost saving per additional child enrolled is around 30 percent.

\section{An Implementable Conditional Cash Transfer Program}

Having established the optimal conditional transfer schedule as an efficiency benchmark, the analysis now turns to the definition of simpler implementable conditional transfer schedules, based on a linear combination of a few observable characteristics. For a given set of variables $Z$ the implementable schedule is the solution to the optimization problem defined in equations (9) and (10). The values for $\beta, \delta_{0}$, and $\delta$ are taken from column (5) of table 2 , with the parameters $\alpha$ and $\lambda$ solved for iteratively, ${ }^{12}$ followed by exploration of combinations of characteristics $Z$ that are easily observable, verifiable by others, and nonmanipulatable by the household. An efficiency criterion for selection requires choosing characteristics that are important correlates of enrollment (to target the children least likely to enroll without a conditional transfer) or that indicate high sensitivity of enrollment to a conditional transfer. In addition to these

12. Starting with general eligibility, the optimization problem in equation 10 is solved for $\alpha$ as a function of $\lambda$, with $\lambda$ adjusted to balance the budget. These parameters are used to compute transfers and define eligibility. This procedure is iterated until there is convergence, that is, no change in eligibility between two consecutive iterations. This is always achieved in fewer than five iterations. 
features, actual implementation of a program requires these criteria to be legally and politically acceptable. This is clearly an issue that every program should address in its own particular context.

In the base model the conditional transfer schedule depends only on gender and birth order of the child, presence of a secondary school in the community, distance to a secondary school if there is not one in the community, and state dummy variables, which are all strong correlates of enrollment. A few alternative specifications are reported later. Note that age of the child is not used because an eligibility criterion based on age could induce perverse behavior, such as parents delaying their children's entry to secondary school to benefit from a larger conditional transfer. The child's birth order, which cannot be manipulated, turns out to capture part of this information. Each variable can be easily observed and verified. In fact, instead of secret eligibility formulas (as currently used for poverty), which offer little room for recourse and accountability, self-registration is possible, with easy verification.

Results are reported in table 5. The birth order parameter indicates that the conditional transfer is highest for the oldest child and decreases by $\$ 12$ for each younger sibling. Girls would optimally receive a premium of $\$ 25$. The main source of variation in conditional transfer is related to distance to school, with a large premium for children who need to travel some distance to school and an additional amount for each kilometer traveled. The program also exhibits some variation across states, with a difference of $\$ 87$ between the extreme cases of Queretaro and Guerrero.

Examples of eligibility and conditional transfer amounts computed with this simple points system are reported in the lower part of table 5. Children with a school in their own community (23 percent of the sample) are not eligible. Their predicted enrollment rate without conditional transfer is 80.5 percent, which is also the rate observed in control communities with a school. By contrast, all the children who do not have a school in their community are eligible for a conditional transfer. ${ }^{13} \mathrm{~A}$ boy who is the oldest child and lives 3 kilometers from a school would receive a conditional transfer of $\$ 213$, whereas the third child would receive only $\$ 190$. If the oldest child is a girl, she would receive $\$ 239$. Cumulating all the disadvantages, a girl who is the oldest child and lives 6 kilometers from a school would receive the highest transfer: $\$ 266$.

This conditional transfer schedule results in an efficiency loss relative to the optimal variable schedule, the cost to be paid for simplicity, and transparency (table 4). Although the number of eligible children is about the same as with the optimal conditional transfer schedule (77.4 percent), the eligibility criteria are not the same. The implementable schedule includes 9 percent of the children not

13. The average distance to school for the 77 percent of children who do not have a school in their community is 3.1 kilometers. Enrollment rates decrease very sharply with distance to school in the control communities, reaching a low of 43 percent for the 19 percent of children who live more than 4 kilometers from school. 
TABLE 5. Optimal Implementable Conditional Cash Transfer Schedule

\begin{tabular}{|c|c|c|c|}
\hline & Base Model & With Illiteracy & Geographic \\
\hline \multicolumn{4}{|l|}{$\begin{array}{l}\text { Conditional transfer formula } \\
\text { (US\$ per year) }\end{array}$} \\
\hline Birth order & -12 & -12 & \\
\hline Male & -25 & -25 & \\
\hline $\begin{array}{l}\text { No secondary school } \\
\text { in the community }\end{array}$ & 476 & 502 & 447 \\
\hline $\begin{array}{l}\text { Distance to secondary } \\
\text { school }[\ln (1+\mathrm{kms})]\end{array}$ & 50 & 49 & 48 \\
\hline Mother illiterate & & 26 & \\
\hline Father illiterate & & 30 & \\
\hline Guerrero & -295 & -351 & -295 \\
\hline Hidalgo & -278 & -327 & -283 \\
\hline Michoacan & -246 & -288 & -253 \\
\hline Puebla & -267 & -317 & -273 \\
\hline Queretaro & -208 & -257 & -214 \\
\hline San Luis Potosi & -260 & -303 & -260 \\
\hline Veracruz & -285 & -333 & -288 \\
\hline \multicolumn{4}{|l|}{$\begin{array}{l}\text { Examples of transfers } \\
\text { by children types in state } \\
\text { of Guerrero (US\$ per year) }\end{array}$} \\
\hline School in the community & Not eligible & Not eligible & Not eligible \\
\hline $\begin{array}{l}\text { Oldest, male, with literate } \\
\text { parents, and school } 3 \text { kilometers } \\
\text { away }\end{array}$ & 213 & 184 & 218 \\
\hline $\begin{array}{l}\text { Third child, male, with literate } \\
\text { parents, and school } 3 \text { kilometers } \\
\text { away }\end{array}$ & 190 & 162 & 218 \\
\hline $\begin{array}{l}\text { Oldest, male, with illiterate parents, } \\
\text { and school } 3 \text { kilometers away }\end{array}$ & 213 & 240 & 218 \\
\hline $\begin{array}{l}\text { Oldest, female, with illiterate parents, } \\
\text { and school } 3 \text { kilometers away }\end{array}$ & 239 & 265 & 218 \\
\hline $\begin{array}{l}\text { Oldest, female, with illiterate parents, } \\
\text { and school } 6 \text { kilometers away }\end{array}$ & 266 & 292 & 245 \\
\hline $\begin{array}{l}\text { Efficiency gain over universal uniform } \\
\text { schedule (percent) }\end{array}$ & 29.4 & 31.0 & 28.5 \\
\hline
\end{tabular}

eligible under the optimal schedule (type II error) and excludes 9 percent of the children eligible under the optimal schedule (type I error). Enrollment of eligible children rises from 58.2 percent without a conditional transfer to 79.1 percent with one. Enrollment is 80.5 percent for noneligible children and 79.4 percent for all children. This implies a 29.4 percent efficiency gain over the universal uniform conditional transfer schedule. Cost per additional child enrolled is $\$ 889$, still about 23 percent cheaper than under the universal uniform schedule but nearly 11 percent more expensive than under the optimal variable schedule.

Alternative implementable schedules that vary the characteristics used to establish eligibility and conditional transfer amounts are now explored 
(table 5). Adding mother's and father's literacy status, important predictors of school enrollment, raises the efficiency gain to 31 percent above the universal uniform schedule. While it can be argued that such subsidies (here computed as $\$ 26$ if the mother is illiterate and $\$ 30$ if the father is illiterate) may give the wrong signal and bias, the return to education, they can also be seen as a way to compensate for the handicap that children of uneducated parents have and to help children catch up.

At the other extreme, how efficient would it be to define a conditional transfer schedule at the community level (although only for poor children)? Doing so leads to an important efficiency gain of 28.5 percent over the uniform conditional transfer schedule. This geographical targeting is interesting because it shows that in the particular case of rural Mexico an important efficiency gain could be obtained by redesigning the conditional transfer program as a school transportation subsidy. A simple transportation subsidy would capture 65 percent of the efficiency gain that the optimal conditional transfer program would garner. The question then arises of how this intervention compares with a supply-side policy that would bring schools closer to where people live. This is beyond the scope of this article, but Coady (2000) estimates that the cost of raising enrollment through a supply-side intervention that increases the number of rural schools would be more than seven times as much as the current Progresa program.

These specific implementable schedules are illustrations of the idea that designing a relatively simple conditional transfer program, with a points system that is transparent and easily verifiable, is indeed feasible and could ensure large efficiency gains.

\section{Comparing Direct Costs and Efficiency Leakages under the Three Schedules}

A key determinant of the relative efficiency of different targeting schedules is their efficiency leakages, namely the magnitude of the transfers that go to children who would attend school without the conditional transfer. This is analyzed in a comparative fashion in figures 4 and 5, where the total transfer cost for each category of children is divided into direct costs (transfers to children that would not otherwise have enrolled, represented in black) and efficiency-leakage costs (transfers to children that would have enrolled anyway, represented with stripes). Differences among the figures are quite telling. Under the universal uniform conditional transfer schedule, leakages are particularly high, especially among children with a high probability of attending school without a conditional transfer. Some 83.2 percent of the total cost is efficiency leakages, leaving an effective direct cost of only 16.8 percent. The optimal variable conditional transfer schedule reduces efficiency leakages by targeting children with a low probability of attending school and increasing the magnitude of the conditional cash transfers (figure 5). Efficiency leakages are reduced to 64.9 percent of total costs, implying an effective direct cost of 36.1 percent. The implementable conditional transfer schedule (not pictured) has an efficiency leakage of 72.5 percent of total costs. Because targeting is simplified and 
Figure 4. Total Annual Direct Costs and Leakage Costs under the Universal Uniform Conditional Transfer Program

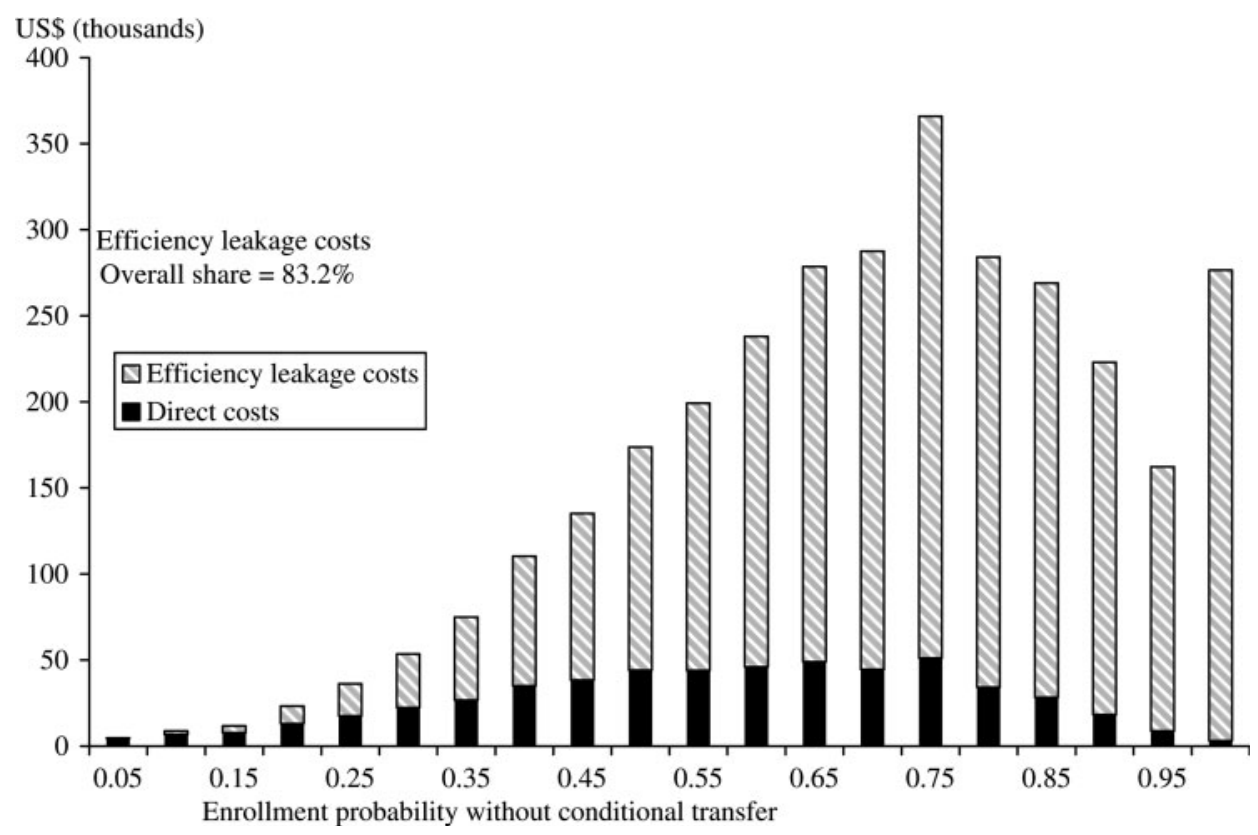

Source: Authors' calculations based on the 1998 Progresa survey.

transparent, it is a compromise between the universal and the optimal variable conditional transfer schedules. Its effective direct cost is 27.5 percent.

In conclusion, the optimal variable conditional transfer schedule could offer a significant efficiency gain in school enrollment and could be implemented through a secret formula like the one Progresa currently uses to target poverty. It may, however, be too complex to administer, and secrecy is not a desirable feature as it makes recourse almost impossible. However, the implementable variable conditional transfer schedule-with its transparent targeting-also results in substantial efficiency gains relative to Progresa's current universal uniform conditional transfers.

\section{Efficient Conditional Cash Transfer Programs and Equity}

Are these optimal and implementable schedules regressive or progressive? In other words, are efficiency gains in enrollment achieved at an equity cost? Conditional transfers driven by efficiency gains indeed raise the issue that maximally efficient programs may be inequitable (Das, Do, and Özler 2005). For this reason eligibility is restricted to poor households. However, when poor households are further targeted, are the resulting transfers regressive or progressive?

Before looking at the distributive effect of targeting among poor households, it is interesting to note that the Progresa transfers themselves were not 
Figure 5. Total Annual Direct Costs and Leakage Costs under the Optimal Variable Conditional Transfer Program

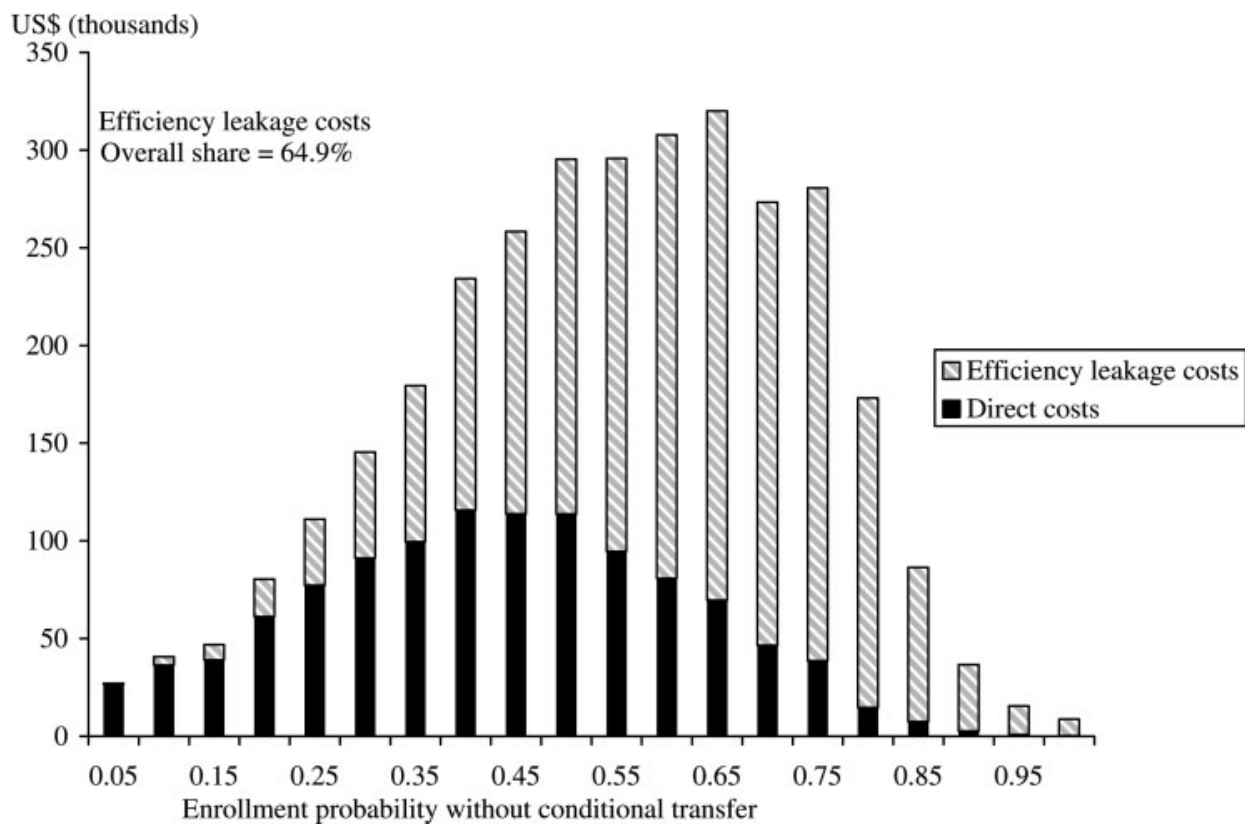

Source: Authors' calculations based on the 1998 Progresa survey.

particularly efficient in reducing poverty or inequality. Indeed, with poverty measured by consumption per capita, the transfers are almost uniformly distributed across levels of per capita consumption (de Janvry and Sadoulet 2003). This article, however, discusses the issue of tradeoff between efficiency and equity using the Progresa welfare index measured in 1997, rather than the income-consumption level, since this is what Progresa uses as a poverty indicator. Figure 6 shows the average distributed transfer with households ranked by the Progresa welfare index. The average transfer distributed by Progresa shows a clear upward trend and thus regressivity among poor households. This is because of the low uptake rate in low welfare classes. By contrast, the average distributed transfer decreases across welfare levels with the optimal variable conditional transfer schedule (from $\$ 160$ to $\$ 140$ ) and is uniform with the implementable schedule. Efficiency gains in implementing conditional transfer programs designed to maximize the effect of the conditionality are thus not achieved at the cost of rising inequality among poor households.

\section{Conclusions}

This article questions whether efficiency gains can be achieved in conditional cash transfer programs by improving targeting among poor households and 
Figure 6. Eligibility and Distributed Transfers by Welfare Index

Average annual distributed transfer (US\$)

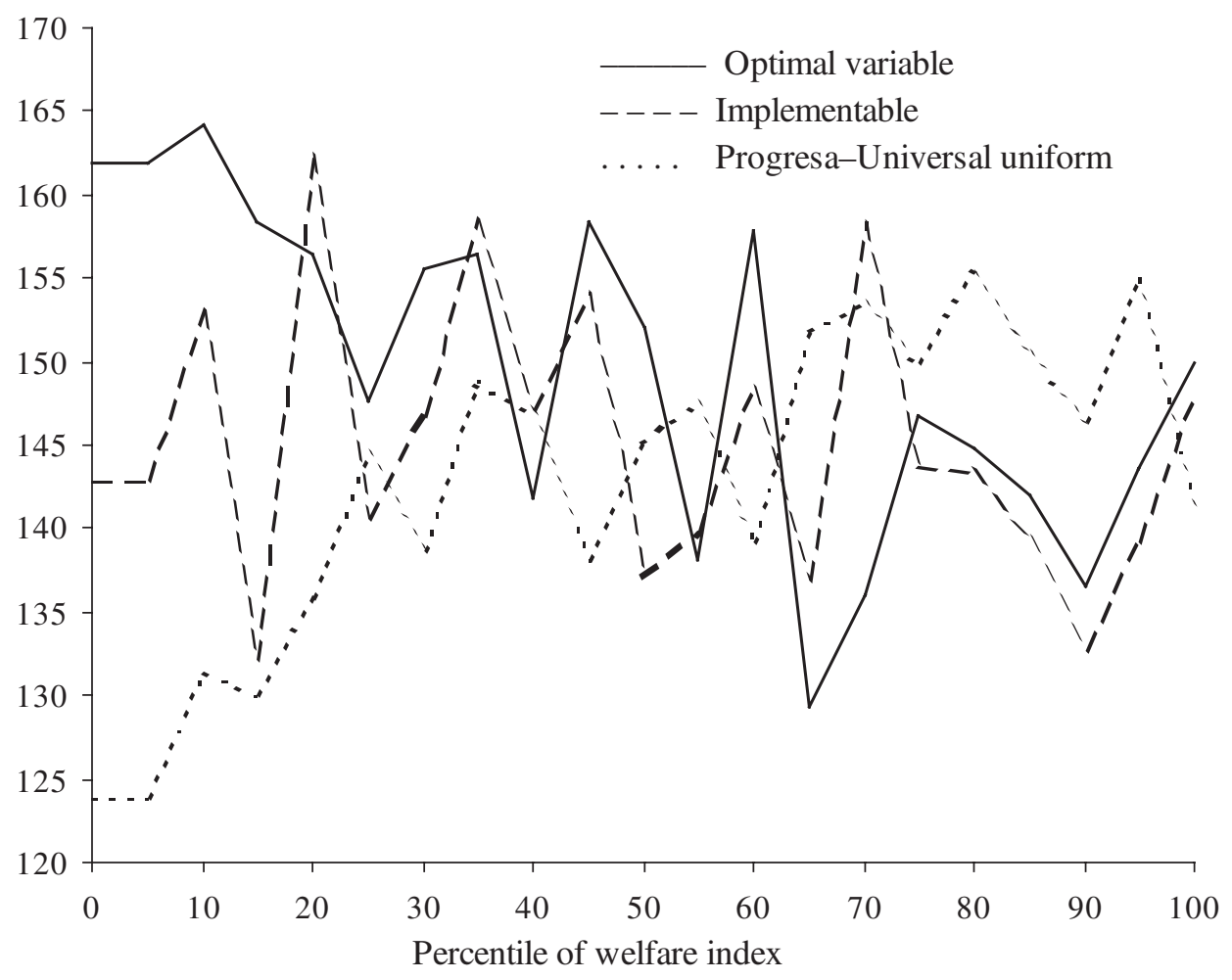

Source: Authors' calculations based on the 1998 Progresa survey.

better calibrating conditional transfers. The efficiency objective is to maximize the impact of the condition imposed on the transfer, in this case gains in school enrollment among poor children. Using the data from the Progresa randomized experiment, the analysis focused on the crucial education decision for children in poor Mexican rural communities-namely whether to continue schooling at the secondary level.

Achieving efficiency gains by targeting and calibrating conditional transfers requires focusing on children who have a high probability of not enrolling in school without a conditional transfer and who have a high response to the amount offered, within the overall program budget constraint. Implementing this program requires predicting school enrollment as a function of the conditional transfer offered and of child, household, and community characteristics. Heterogeneity in responses shows that age, ethnicity, and presence of a school in the community lead to large differences in enrollment. Three alternative targeting and calibration schedules were then compared: the current Progresa schedule of universal uniform conditional transfers; an optimal schedule of variable conditional transfers; and a 
schedule of implementable conditional transfers, where the criteria used for targeting and calibration are easily observable, verifiable by others, and nonmanipulatable by the household. In setting up a new program, a pilot experiment would need to be used to estimate the enrollment probability model necessary to establish the targeting and calibration formulas.

The optimal schedule is found to offer a 44 percent efficiency gain over the universal conditional transfer schedule and the implementable schedule a 29 percent gain. The optimal schedule reduces efficiency leakages (receipt of transfers by children who would attend school without a conditional transfer) from 83 percent of total costs to 65 percent, and the implementable schedule to 73 percent. These efficiency gains are not achieved at the cost of rising inequality among poor households.

The overall conclusion is thus that large efficiency gains can be achieved in implementing what are in many countries very expensive conditional cash transfer programs for human capital formation among poor households if rules for targeting and calibration of conditional transfers are designed to maximize the effect of the conditionality.

\section{REFERENCES}

Alderman, Harold. 2001. "Multi-Tier Targeting of Social Assistance: The Role of Intergovernmental Transfers." World Bank Economic Review 15 (1):33-53.

—. 2002. "Do Local Officials Know Something We. Don't? Decentralization of Targeted Transfers in Albania.” Journal of Public Economics 83 (3):307-457.

Behrman, Jere, and Petra Todd. 1999. "Randomness in the Experimental Samples of PROGRESA.” International Food Policy Research Institute, Washington, D.C.

Behrman, Jere, Piyali Sengupta, and Petra Todd. 2001. "Progressing Through Progresa: An Impact Assessment of a School Subsidy Experiment." University of Pennsylvania, Department of Economics Philadelphia.

Bourguignon, François, Francisco Ferreira, and Philippe Leite. 2002. "Ex.-Ante Evaluation of CCT Programs: The Case of Bolsa Escola.” Policy Research Working Paper 2916. World Bank, Washington, D.C.

Coady, David. 2000. "The Application of Social Cost-Benefit Analysis to the Evaluation of Progresa." International Food Policy Research Institute, Washington, D.C.

Das, Jishnu, Quy-Toan Do, and Berk Özler. 2005. "Reassessing Conditional Cash Transfer Programs." World Bank Research Observer 20 (1):57-80.

Gertler, Paul. 2004. "Do Conditional Cash Transfers Improve Child Health? Evidence from Progresa's Control Randomized Experiment.” American Economic Review 94 (2):336-41.

de Janvry, Alain, and Elisabeth Sadoulet. 2003. "Dépasser Bono: Comment rendre plus efficiente l'aide au développement.” Revue D’économie Du Développement 4:63-76.

de Janvry, Alain, Frederico Finan, and Elisabeth Sadoulet. 2001. "Decomposing the Channels of Influence of Ccts in a Structural Model of Educational Choice.” University of California at Berkeley. http:// are.Berkeley.edu/ sadoulet/

Morley, Samuel, and David Coady. 2003. "From Social Assistance to Social Development: A Review of Targeted Education Subsidies in Developing Countries.” Center for Global Development and International Food Policy Research Institute, Washington, D.C.

Ravallion, Martin. 2003. "Targeted Transfers in Poor Countries: Revisiting the Trade-Offs and Policy Options.” Policy Research Working Paper 3048. World Bank, Washington, D.C. 
Ravallion, Martin, and Quentin Wodon. 2000. “Does Child Labor Displace Schooling? Evidence on Behavioral Responses to an Enrollment Subsidy.” Economic Journal 110 (462):158-75.

Rawlings, Laura, and Gloria Rubio. 2005. "Evaluating the Impact of Conditional Cash Transfer Programs." World Bank Research Observer 20 (1):29-55.

Schady, Norbert. 2002. "Picking the Poor: Indicators for Geographic Targeting in Peru." Review of Income and Wealth 48 (3):417-33.

Schultz, T. Paul. 2004. "School Subsidies for the Poor: Evaluating the Mexican Progresa Poverty Program.” Journal of Development Economics 74 (1):199-250.

Skoufias, Emmanuel. 2000. "Is PROGRESA Working? Summary of the Results of an Evaluation by IFPRI." FCND Briefs International Food Policy Research Institute, Food Consumption and Nutrition Division, Washington, D.C.

van de Walle, Dominique. 1998. “Targeting Revisited.” World Bank Research Observer 13 (2):231-48. 